was being designed for the Department of Health, as well as equipment to record blood pressures of patients undergoing surgical operations under anæsthesia. The geophysical branches were reorganised during the year to provide for improved operation of the magnetic survey, ionosphere, seismology and oceanography activities of the Department, while the strengthening of the staff of the Geological Survey contributed chiefly to progress with coal surveys and surveys of sites for hydro-electric dams. Studies in vulcanology and the use of geothermal power were a]so initiated.

\section{BRITISH JOURNAL OF APPLIED PHYSICS \\ A NEW MONTHLY PUBLICATION}

T

HE Institute of Physics has always stressed the importance of the application of physics in industry, and, as early as 1923, it commenced the publication of the "Physics in Industry" series. This series of monographs contains lectures and symposia given before the Institute, its branches and subject groups, and specially written reports on branches of applied physics. From time to time during the past fifteen years, contributions devoted to applied physics have also appeared in the Institute's monthly Journal of Scientific Instruments, and for the past two years the applied physics articles have been gathered together into a separate section of the Journal, which has been given the extended title of Journal of Scientific Instruments and of Ploysics in Industry. In January of this year the Institute launched a new monthly publication, the British Journal of Applied Physics*, the primary object of which is to announce new applications of physics, especially in industry, and developments of those already known. With the commencement of this new journal, the Journal of Scientific Instruments has reverted to its original title and to its original object with articles devoted solely to scientific instruments and apparatus.

The first three numbers of the British Journal of Applied Physics have a format similar to that of the Journal of Scientific Instruments, and it is evident that a high standard of presentation is being aimed at. Original papers of scientific merit, special survey articles in the field of applied physics, selections from the lectures, and discussions and symposia arranged by the Institute and its groups and branches at home and overseas are to form the main contents of the new Journal. In addition, there are book reviews, correspondence, technical notes and news items. Special articles which have so far appeared are by Sir Philip Morris on scientific education, the sub. stance of which he delivered at the inaugural meeting of the Education Group of the Institute on October 5, 1949 ; by J. Moore on chemical and physical properties of mubber ; and by T. Bedford on environmental warmth and human comfort. The original contri. butions, which average four per issue, cover a very wide field and include articles on paper, electronics, photo-elasticity and rotating mechanisms. In the March number the leading article is a summarized report of the proceedings of the meeting, held at Buxton in May 1949, on the investigation of biological systems by the electron microscope and by $\mathrm{X}$-ray analysis.

* British Journal of Applied Physics. (Monthly.) Vol. 1, No. 1 January. Pp. 32. (London: Institute of Physics, 1950.) 6s.; annua subscription, 608 .
The Couneil of the Royal Society has made a grant towards the cost of the new venture, and the Council of the Physical Society has given its support and encouragement. The new Journal will be welcomed by the large number of physicists now employed in industry, and it will prove valuable to those engaged on fundamental physics by giving them an insight into the problems and developments in the rapidly expanding industrial field.

\section{AFFORESTATION IN EUROPE}

MONG the subjects considered in the September 1949 issue of Forestry Abstracts (11, No. 1 ; Oxford : Commonwealth Forestry Bureau) are some brief reviews on afforestation. J. Tuzson describes some experiments for afforestation on the great plain of Hungary. The trees being experimented with are both exotic conifers and hardwoods. The somewhat difficult soil and climatic factors of the great Hungarian plain make forestry by no means easy; for that reason the experiments so far undertaken are of very considerable interest, and the paper merits study. A bulletin on the afforestation of the Plateau of Millevaches, by M. Vazeilles, gives an account of the reclamation and afforestation of some 156,000 hectares of barren heathland in the Limousin. Various exotics are being experimented with in order to find, it is said, the most suitable species for the area. From the afforestation work which was undertaken between the two World Wars in the Auvergne mountains and the small plateaux, one would have thought that the indigenous species would probably give better results than some of the more popular exotics.

Mountain planting in Italy is discussed by $\mathbf{M}$. Zajaczkowski in the Quarterly Journal of Forestry $(43 ; 1949)$. This paper deals with methods of planting used on steep eroded slopes of the Apennines and is of value, since it discusses three methods which should be well known nowadays in dealing with similar types of afforestation. The methods are (1) cultivated patches (bucche), (2) contour terracing (gradoni), (3) discontinuous terracing (piazzole) between widely spaced contour terraces. Methods and cost and a brief account of nursery practice are given.

Lastly, there is an article in Gozd. Vestn., $5(1,2)$; 1946 (Sloven) by V. Beltram, entitled "Afforestation of the Karst is no Problem". The author, making use of the report of the Karst Afforestation Commission, reviews forestry work done between 1886 and 1911 in the Karst region of Slovenia in the light of his own experience in the Dalmatian islands, which are also of Karst type. The work was exclusively a planting one and no direct sowings were made; and it also favoured the exclusive use of Pinus nigra, which constituted 91 per cent of the planting stock. It was found, however, that owing to the long distances between the nurseries and the planting sites, and partly because Pinus nigra is not suited to the region, 71 per cent of the entire stock had to be replaced. On the other hand, Pinus sylvestris, of which small amounts were planted, is found to do better and to regenerate abundantly. From his experience the author advocates sowing rather than planting, since the former is 60 per cent cheaper, and he describes the methods he would propose to use. 